\title{
Explanatory Style as a Risk Factor for Illness ${ }^{1}$
}

\author{
Christopher Peterson ${ }^{2}$ \\ University of Michigan
}

\begin{abstract}
Some have speculated that explanatory style puts an individual at risk for illness. Study 1 supports this hypothesis by showing that college students who believe that stable + global factors caused bad events experienced more days of illness in the following month and visited physicians more frequently in the following year than students who explain bad events with unstable + specific causes. These findings held even when level of previous illness was controlled. Study 2 explores some of the possible links between explanatory style and poor health. College students who believe that stable + global factors caused bad events reported more unhealthy habits, lower efficacy to change these habits, and more stressful occurrences than students who explain bad events with unstable + specific causes.
\end{abstract}

KEY WORDS: explanatory style; health; illness.

The germ model is dead. Illness is now viewed in terms of the interaction among biological, psychological, and social factors. Consistent with this expanded conception, researchers are currently attempting to identify psychological precursors of health and illness (e.g., Jemmott \& Locke, 1984). Various theorists suggest that such psychological states as pessimism, helplessness, hopelessness, and apathy are among the important psychological risk fac-

\footnotetext{
${ }^{1}$ Thanks are expressed to Connie Burton for assistance in gathering data, and to Martin Seligman and Lisa Bossio for advice in preparing this paper. Neil Jacobson and several anonymous reviewers also made helpful suggestions that are gratefully acknowledged. Some of these data were presented at the 94th Annual Convention of the American Psychological Association, Washington, D.C., August 1986.

${ }^{2}$ Address all correspondence to Christopher Peterson, Department of Psychology, University of Michigan, 580 Union Drive, Ann Arbor, Michigan 48109.
} 
tors for illness (e.g., Antonovsky, 1984; Engel, 1971; Kobasa, 1979; Lazarus, 1979; Lefcourt, 1973; Richter, 1957; Rodin, Timko, \& Anderson, 1985; Seeman \& Seeman, 1983). However, clear evidence for a link between these negative states and illness is lacking.

Research in the learned helplessness tradition shows that humans and animals exposed to uncontrollable events learn that responses and outcomes are unrelated. They expect to be helpless in the future, and this negative outlook may then produce a host of difficulties for them. Perhaps susceptibility to illness is one of these difficulties (Peterson \& Seligman, 1984). Explanatory style is the individual's habitual tendency to choose certain kinds of causal explanations for bad events (Peterson \& Seligman, 1984). This individual difference has been extensively examined in studies of the attributional reformulation of the helplessness model of depression where it is thought to channel the effects of uncontrollable bad events (Abramson, Seligman, \& Teasdale, 1978).

According to the helplessness reformulation, a person encountering a bad event asks, "Why did this occur?" The answer to this causal question affects the person's response. Three dimensions of causal explanation are deemed important. An internal explanation ("it's me") is more likely to result in a loss of self-esteem than is an external explanation ("it's the economy"). A stable explanation ("It's going to last forever") is more likely to produce a long-lasting reaction than is an unstable explanation ("it was just one of those days"). A global explanation ("it's going to undercut everything I do") is more likely to lead to a pervasive reaction than is a specific explanation ("it's the heat in that place").

A person's explanatory style is one of the determinants of the particular explanation chosen when that person encounters a bad event (Peterson, Bettes, \& Seligman, 1985). Some people favor internal, stable, and global explanations, while other people favor external, unstable, and specific explanations. The former individuals are more at risk for depression, demoralization, passivity, failure, and other helplessness deficits than are the latter individuals (Peterson \& Seligman, 1984).

In the first investigation reported here, the relationship between explanatory style and subsequent illness was directly assessed in a sample of college students. In the second investigation, some of the possible links between explanatory style and poor health were explored, again in a sample of college students. I chose to study illness among mostly healthy young adults because this research program is just beginning and research with student subjects is inexpensive and convenient. Generalization of findings to more seriously ill groups must necessarily be cautious.

In Study 1, subjects completed questionnaires at three specific times. At Time One, explanatory style and baseline measures of depression and ill- 
ness (i.e., number of days ill in the past month) were assessed. At Time Two, 4 weeks later, illness was again measured in the same way. Finally, at Time Three, 1 year later, subjects were mailed a questionnaire asking them to report how many visits to a physician they had made during the past year. Here are the major questions addressed: (1) Does explanatory style predict illness during the following month? (2) Does explanatory style predict the number of doctor visits during the following year? (3) Do these relationships occur when initial illness and depression are held constant?

\section{STUDY 1}

\section{Method}

Subject and Procedure. The research began during the fall of 1984. Research participants were 172 introductory psychology students ( 57 males, 115 females) at Virginia Tech, who received extra credit toward their final grade. At Time One, 20 to 30 subjects at a time met in single sessions to complete the Beck Depression Inventory (BDI), the Modified Attributional Style Questionnaire (ASQ), and the Illness Scale. At Time Two, approximately 4 weeks later (spanning the weeklong Thanksgiving break), 170 of these subjects $(=99 \%)$ returned to again complete the Illness Scale. (Subjects also completed several other questionnaires at both times, but these are not relevant to the present research). At Time Three, approximately 1 year later, subjects were mailed a brief questionnaire and a stamped envelope addressed to the researcher. They were asked to report the number of visits they had made to a physician for diagnosis and/or treatment of an illness during the past year, since the time they had originally completed the Time One questionnaires. In response to the letter, 105 subjects mailed back the questionnaire. A second letter several weeks later resulted in another 41 responses. In all, then, 146 subjects $(=86 \%)$ provided Time Three data.

Here are brief descriptions of the measures completed by the subjects:

Beck Depression Inventory. The BDI is a 21 -item self-report questionnaire that assesses the severity of common depressive symptoms like sadness, sleep disturbance, and suicidal ideation (Beck, 1967).

Modified Attributional Style Questionnaire. This questionnaire is an expanded version of the one described by Peterson et al. (1982), employing the same instructions and format. Subjects are presented with 24 hypothetical bad events involving themselves. For instance, the events included "your steady romantic relationship ends" and "after your first term at school, you are on academic probation." In each case, they are asked to imagine the event happening to them. They then write the "one major cause of the event" and 
rate it in terms of internality $(=7)$ versus externality $(=1)$ and stability + globality $(=7)$ versus instability + specificity $(=1)$. The internality rating answers the question "Is the cause of this event something about you or something about other people or circumstances?" The stability + globality rating answers the question "Is the cause of this event something that will persist across time and affect many areas of your life or something that will not be present again and will affect few situations that you encounter?"'(Stability and globality were collapsed for efficiency in Study 1 since they are usually highly redundant; see Peterson \& Villanova, 1986; Peterson, Villanova, \& Raps, 1985). The ratings of the 24 events are averaged separately for internality and stability + globality.

Illness Scale. This self-report measure of illness asks subjects to list all of the illnesses experienced during the past 30 days (Suls \& Mullen, 1981). For each illness, the subjects describe the date that the symptoms were first noticed and the date that the symptoms were last present. The degree of illness is then calculated as the number of different days during the month that at least one symptom was present.

Doctor Visits: In the letter sent to the subjects, the following question was asked: "Would you please indicate in the space below the number of times you have visited a physician since last Thanksgiving for diagnosis and/or treatment of an illness? Do not include routine checkups or visits because of an injury (like a broken leg)."

\section{Results}

Means, standard deviations, and reliabilities of the measures are shown in Table I. Also presented there are the correlations between Time One variables and Time Two illness scores and Time Three doctor visits. The questions of concern are answered in the affirmative for stable + global explanatory style. First, this individual difference predicted the number of days ill in the following year. Second, it predicted the number of doctor visits during the following year. Third, these relationships held even when initial illness and depression were partialed out. Internality was not associated with subsequent illness.

Internality and the stability + globality measure were uncorrelated $(r=-.03$, n.s. $)$. Internality was not related to BDI scores $(r=.06$, n.s. $)$, but stability + globality were positively associated $(r=.39, p<.001)$. Time One illness was unrelated to any of the other Time One measures.

To illustrate the results more concretely, I calculated the mean number of days ill in the following month and the mean number of doctor visits in the following year for subjects in the upper and lower quartiles of stable + global explanatory style. Subjects who favored stable + global explanations reported twice as many days ill (8.56 vs. 3.70) and almost four times as many doctor visits ( 3.56 vs. .95 ) as subjects who favored unstable + specific explanations. 


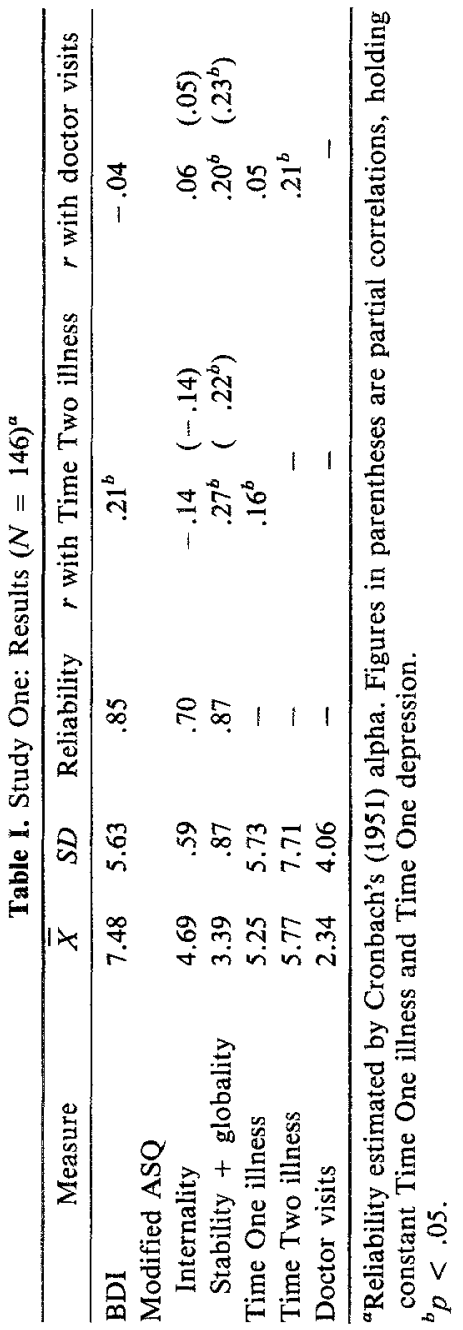


Of the subjects reporting illnesses at Time Two, 95\% described colds, sore throats, or flus. One or two individuals reported each of these: pneumonia, ear infection, venereal disease, and mononucleosis. In other words, all of the illnesses were infectious. Although subjects at Time Three were not asked to describe the illness that brought them to a physician, some small number of them did so. Every illness described was infectious.

\section{Discussion}

These findings support the prediction that explanatory style puts an individual at risk for illness. Explaining bad events with chronic and pervasive causes foreshadows a later infectious disease. Explanatory style warrants further attention in the emerging field of health psychology. In light of the recent suggestion that the attempt to explain illness in psychological terms is "folklore" (Angell, 1985), the present results are important. They move beyond case histories in demonstrating that psychological states can make disease more versus less likely. Explanatory style and infectious illness probably affect each other, and reciprocal influence between these variables and depression is also possible (cf. Peterson \& Seligman, 1984; Schleifer, Keller, Siris, Davis, \& Stein, 1985). At best, Study 1 captures only one causal path, but perhaps it is the most intriguing: Explanatory style foreshadows illness.

\section{STUDY 2}

The correlations found in Study 1 are naked ones, providing no hint about what links explanatory style to illness. A number of routes are possible. (1) Perhaps individuals who offer stable and global explanations become passive in the face of disease (Seligman, 1975). (2) Similarly, perhaps individuals with a negative explanatory style neglect the basics of health care in the first place (Becker, 1974; O'Leary, 1985; Wallston \& Wallston, 1982). (3) Further, people who offer stable and global explanations for bad events tend not to be good problem-solvers (Peterson \& Seligman, 1984) and thus may experience more bad life events, making illness more likely (Rabin \& Streuning, 1976). (4) Yet another possible pathway is loneliness and lack of social support (Anderson, Horowitz, \& French, 1983; Cobb, 1976). (5) Finally, explanatory style may directly affect one's immune system (cf. Laudenslager, Ryan, Drugan, Hyson, \& Maier, 1983).

In Study 2, several (though not all) of these pathways were investigated in a cross-sectional study. These subjects completed various questionnaires, including measures of explanatory style, physical illness, healthy versus un- 
healthy habits, healthy versus unhealthy responses to illness, beliefs about the link between behaviors and health, self-efficacy to perform healthpromoting behaviors, stressful life events, and social support.

\section{Method}

Subjects and Procedure. Research participants were 126 introductory psychology students (52 males, 74 females) at Virginia Tech, who received extra credit toward their final grade. Subjects met in groups of 20 to 30 in a single session to complete the questionnaires. The following measures were completed by each research participant:

Modified Attributional Style Questionnaire. This questionnaire is identical to the one used in Study 1 except that ratings for stability and globality are made separately and then combined. So, subjects provide causal explanation on 7-point scales according to its internality, stability, and globality. The stability and globality ratings are then averaged.

Questions About Physical Health. This questionnaire poses four questions about the subject's health:

1. In the past 12 months, how many different times were you ill?

2. In the past 12 months, how many different times did you visit a physician for diagnosis and/or treatment of an illness (do not include injuries like a broken leg)?

3. Are you ill right now? definitely no maybe definitely yes

4. On the whole, how would you rate your physical health?

The last question is answered on a 7-point rating scale, where $1=$ poor and 7 = excellent.

Healthy versus Unhealthy Habits. This questionnaire asks subjects about eight habits arguably related to good or bad health (cf. Taylor, Denham, \& Ureda, 1982): eating a balanced diet, avoiding salt, avoiding fat, exercising regularly, eating breakfast, not smoking, not drinking more than one glass of wine/beer/liquor per day, and sleeping 8 hours every night. Subjects report their adherence to each habit on a 7-point rating scale, where $1=$ never and 7 = always. (A ninth unhealthy habit - being overweight - was assessed by asking subjects to report their heights and weights. Only 1 subject out of 126 exceeded "normal" weight limits by more than $20 \%$. Accordingly, obesity was not further studied in this sample.)

Responses to Illness. This questionnaire asks subjects about six possible responses to illness: staying home and taking it easy, drinking more fluids than usual, getting more sleep than usual, going about usual activities, fol- 
lowing a balanced diet, and seeing a doctor and following his/her advice. Again, each question is answered on a 7-point rating scale, where $1=$ never and $7=$ always.

Beliefs About Life-Style. The purpose of this questionnaire is to assess the respondent's outcome expectancy and efficacy expectancy with respect to health and illness (Bandura, 1986). In other words, does the subject believe there exists a link between particular behaviors and physical health? And does the subject believe that he or she can perform these behaviors?

For each of the eight behaviors in the already-described Habits questionnaire, plus the habit of being overweight, a subject is asked the following question:

Do you believe that this habit determines how healthy you are and how long you will live?

$$
\text { definitely no maybe definitely yes }
$$

Then subjects were asked to provide a percentage from 0 to $100 \%$ for each of these behaviors in response to the question: "Assuming that you wished to adopt or change this habit, how confident are you that you could do so? Use $0 \%$ to mean that you are not at all confident; use $100 \%$ to mean that you are completely confident; use intermediate percentages to mean you have intermediate degrees of confidence."

College Schedule of Recent Experience. This life events questionnaire is designed for college students (Marx, Garrity, \& Bowers, 1975). For each of 47 stressful occurrences (e.g., have been found guilty of minor violations of the law), subjects indicate the number of times they experienced it during the past 12 months: $0,1,2,3,4$ or more. This questionnaire is scored simply by adding these ratings.

Social Support Inventory. This questionnaire measures the degree to which subjects experience social support (Barrera, Sandler, \& Ramsay, 1981). It presents respondents with 40 supportive activities (e.g., someone let you know that you did something well) and asks them to indicate with a 5-point scale the frequency that each happened during the past 4 weeks, where $1=$ not at all and $5=$ about every day.

\section{Results}

To simplify presentation of the data, composite scores were formed by averaging responses to the Habits questionnaire, the Responses to Illness questionnaire, to the outcome expectancy items on the Life-Style questionnaire, and to the efficacy expectancy items on the Life-Style questionnaire, reverse-scoring items where appropriate. Responses to the four questions about physical health were first normalized and then combined into an equally 
weighted composite. Means, standard deviations, and reliabilities of the measures are presented in Table II. The reliabilities ranged from low (responses to illness, internal explanatory style, healthy habits) to moderate (efficacy expectations, illness, outcome expectations) to excellent (life events, stable + global explanatory style, social support). Consistent with the findings in Study 1, the composite measure of illness in Study 2 correlated with stable + global explanations for bad events $(r=.25, p<.003)$ but not with internal explanations $(r=.00$, n.s.).

I calculated the correlations between the measures of possible links and explanatory style on the one hand and between them and illness on the other hand. Stable + global explanatory style correlated negatively with healthy habits $(r=-.26, p<.05)$ and efficacy expectations $(r=-.20, p<.05)$ and positively with life events $(r=.25, p<.05)$. Internality correlated negatively with social support $(r=-.23, p<.05)$. The composite measure of illness correlated negatively with healthy habits $(r=-.23, p<.05)$ and positively with life events $(r=.18, p<.05)$ but not with efficacy expectations $(r=-.14$, n.s.).

These correlations suggest that unhealthy habits and stressful life events may mediate the link between explanatory style and physical illness. Possibly implicated is low self-efficacy to promote one's own health. When these variables were partialed from the correlation between stable + global explanatory style and illness, this correlation was attenuated as one would expect. So, with healthy habits held constant, the explanatory style-illness correlation became $.20(p<.05)$. With life events held constant, the corre-

Table II. Study Two: Means and Reliabilities of Measures $(N=126)^{a}$

\begin{tabular}{lccc}
\hline \multicolumn{1}{c}{ Measure } & $\bar{X}$ & $S D$ & Reliability \\
\hline Modified ASQ & & & \\
$\quad$ Internality & 4.74 & .43 & .39 \\
$\quad$ Stability + globality & 4.40 & .70 & .90 \\
Illness & & & \\
$\quad$ Times ill & 2.84 & 2.64 & \\
$\quad$ Doctor visits & 1.66 & 2.30 & \\
Current illness & 1.55 & .83 & \\
$\quad$ Health in general & 4.71 & .99 & \\
$\quad$ Composite (see text) & 0 & 2.83 & .68 \\
Healthy habits & 4.59 & .72 & .40 \\
Response to illness & 4.94 & .75 & .31 \\
Outcome expectations & 2.52 & .28 & .75 \\
Efficacy expectations & 77.27 & 11.69 & .60 \\
Life events & 33.64 & 15.22 & .85 \\
Social support & 2.53 & .74 & .96 \\
\hline
\end{tabular}

${ }^{a}$ Reliability estimated by Cronbach's (1951) alpha. 
lation between explanatory style and illness became $.21(p<.05)$. Finally, partialing out self-efficacy reduced the correlation slightly to $.23(p<.05)$. When habits, life events, and self-efficacy were simultaneously partialed from the correlation between explanatory style and illness, it became nonsignificant $(r=.15)$. Note that no single link, at least as measured here, is sufficient to explain why explanatory style puts someone at risk for illness. Whatever bridges the two must be complex.

\section{Discussion}

Because the data in Study 2 are cross-sectional, interpretation is difficult. The results nevertheless imply that explanatory style may affect subsequent illness in at least several ways. Not investigated here is the possibility that explanatory style is related to immune function, although pilot work by Kamen, Seligman, and Rodin (1986) find that explanatory style correlates with immunosuppression.

Here is a process compatible with the present results. Individuals who offer stable + global explanations for bad events tend to behave in unhealthy ways because they feel unable to change their bad habits. They are likely to fall ill. At the same time, these individuals tend to create problems for themselves, and they experience stressful life events. Again, they are likely to fall ill. Compounding matters even further for these pessimistic individuals is the possibility that they tend to fight off disease poorly.

Longitudinal research is obviously needed to test this hypothesized process. In such an investigation, one must be alert to the possibility of bidirectional influence among all the variables. The origins of explanatory style have received much less attention than its consequences (cf. Peterson \& Seligman, 1984), but it is conceivable that possible links between explanatory style and poor health like bad life events and unhealthy habits are additionally determinants of explanatory style.

Researchers should probably not settle prematurely on one particular mechanism to bear the burden for explaining correlations between psychological states and illness. In a sample of college students, it is not surprising that outcome expectancies and social support bear little relationship to explanatory style or illness. In a sample of less educated, older, and/or more isolated individuals, these variables might play an important role in linking negative outlooks with illness.

\section{GENERAL DISCUSSION}

Taken together, the two studies reported here document a link between explanatory style and illness, and suggest that this link may be mediated in 
several different ways. That a cognitive individual difference able to be assessed with a brief questionnaire can predict subsequent health and illness is an exciting finding. Still, there are some puzzles in the present data.

For instance, internality did not correlate with illness. If anything, the trend was in the opposite direction in Study 1. Why this should be so is unclear. There are hints in the literature that internal explanatory style is not a unitary dimension, that it subsumes two quite different causal explanations: characterological attributions ("I'm a wretched person") and behavioral attributions ("I made a mistake") (e.g., Peterson, Schwartz, \& Seligman, 1981). Not surprisingly, internality tends to be the least reliable dimension of explanatory style and to bear the least coherent relationship to other variables (Peterson \& Villanova, 1986; Peterson, Villanova, \& Raps, 1985). Perhaps these preclude a consistent relationship between internality and illness.

Another puzzle is that in Study 1, Time One illness was not related to explanatory style. To the degree that explanatory style is a stable trait, one would expect it to correlate with illness at all times. Perhaps explanatory style is more in flux than heretofore proposed. As I earlier noted, the relationship between illness and explanatory style may show a reciprocal influence. What this means is that explanatory style may change over time, although at any given moment it is a demonstrable risk factor for subsequent difficulties.

Three qualifications of the present research must be made. First, the obtained correlations between explanatory style and illness are quite modest in magnitude. On the one hand, this is hardly surprising since health and illness have numerous and complex determinants. On the other hand, perhaps the present correlations underestimate the actual relationship between explanatory style and illness. Measures were not perfectly reliable. The range of illness among subjects was truncated. The time spans studied may not have been optimal.

Second, the measures of illness relied on self-report by the research participants. Although these measures showed a consistent relationship with explanatory style, their relationship to an "objective" medical examination is not entirely clear. In favor of these measures, they have face validity and have been used in previous research. Kobasa (1979) demonstrated that selfreport of simple and specific illnesses agrees highly with medical diagnosis.

Also in favor of these measures is that their most likely contaminant (a response set of complaining) can be ruled out in Study 1, since the procedure of partialing out initial depression and initial illness controls for complaining. If subjects were simply complaining (or not) in response to all of the questionnaires, one would expect higher correlations between the contemporaneous measures than between these measures and reports of illness 30 days later or 365 days later. That was not the case. 
Still, there is no single criterion of health. The researcher must look for convergence across different measures. The present studies show that explanatory style is related to "illness" as measured by self-reported symptoms and doctor visits. Several other recent studies find correlations between explanatory style and "illness" as measured by physician examination, early mortality, and poor immune function (Peterson \& Seligman, 1987). Thus, I have confidence in my conclusion that explanatory style is related to physical illness.

The third limitation here is that the research subjects were for the most part healthy young adults. This may have worked against finding any significant relations between psychological factors and illness. By this view, the present correlations are particularly notable. But generalization to populations at risk for serious illness is not warranted without further research.

In sum, the present studies examined the popular hypothesis that negative psychological states are a risk factor for illness. Explanatory style predicted the degree of infectious disease during the following month and the number of doctor visits during the following year, even when the level of previous illness was controlled. The possible links between explanatory style and illness include unhealthy habits like poor nutrition, smoking, and drinking, stressful life events, and-possibly-low self-efficacy to promote one's own health.

It may someday be possible to identify individuals at risk for illness by the way that they explain bad events. I have elsewhere described how explanatory style can be assessed through the content analysis of causal explanations that occur in verbal material (Peterson, Bettes, \& Seligman, 1985; Peterson, Luborsky, \& Seligman, 1983; Peterson \& Seligman, 1984, 1984). This means that explanatory style can be scored retrospectively from archived material like letters, diaries, and open-ended interviews. Perhaps it will someday be possible to change an unhealthy explanatory style with the known techniques of cognitive therapy (Beck, Rush, Shaw, \& Emery, 1979), increasing the quality and quantity of life.

\section{REFERENCES}

Abramson, L. Y., Seligman, M. E. P., \& Teasdale, J. D. (1978). Learned helplessness in people: Critique and reformulation. Journal of Abnormal Psychology, 87, 49-74.

Anderson, C. A., Horowitz, L. M., \& French, R. deS. (1983). Attributional style of lonely and depressed people. Journal of Personality and Social Psychology, 45, 127-136.

Angell, M. (1985). Disease as a reflection of the psyche. New England Journal of Medicine, $312,1570-1572$.

Antonovsky, A. (1984). The sense of coherence as a determinant of health. In J. D. Matarazzo, S. M. Weiss, J. A. Herd, and N. E. Miller (Eds.), Behavioral health: $A$ handbook of health enhancement and disease prevention (pp. 114129). New York: Wiley.

Bandura, A. (1986). Social foundations of thought and action: A social cognitive theory. Englewood Cliffs, New Jersey: Prentice-Hall. 
Barrera, M., Sandler, I. N., \& Ramsey, T. B. (1981). Preliminary development of a scale of social support: Studies on college students. American Journal of Community Psychology, 9, 435-447.

Beck, A. T. (1967). Depression: Clinical, experimental, and theoretical aspects. New York: Hoeber.

Beck, A. T., Rush, A. J., Shaw, B. F., \& Emery, G. (1979). Cognitive therapy of depression. New York: Guilford Press.

Becker, M. H. (1974). The health belief model and personal health behavior. Thorofare, New Jersey: Slack.

Cobb, S. (1976). Social support as a moderator of life stress. Psychosomatic Medicine, 38, 300-314.

Cronbach, L. J. (1951). Coefficient alpha and the internal structure of tests. Psychometrika, $16,297-334$.

Engel, G. L. (1971). Sudden and rapid death during psychological stress: Folklore or folkwisdom? Annals of Internal Medicine, 74, 771-782.

Jemmott, J. B., \& Locke, S. E. (1984). Psychosocial factors, immunologic mediation, and human susceptibility to infectious disease: How much do we know? Psychological Bulle$\operatorname{tin}, 95,78-108$.

Kamen, L. P., Seligman, M. E. P., \& Rodin, J. (1986). Unpublished data, University of Pennsylvania.

Kobasa, S. C. (1979). Stressful life events, personality, and health: An inquiry into hardiness. Journal of Personality and Social Psychology, 37, 1-11.

Laudenslager, M. L., Ryan, S. M., Drugan, R. C., Hyson, R. L., \& Maier, S. F. (1983). Coping and immunosuppression: Inescapable but not escapable shock suppresses lymphocyte proliferation. Science, $221,568-570$.

Lazarus, R. S. (1979). Positive denial: The case of not facing reality. Psychology Today, 13, 44-60.

Lefcourt, H. M. (1973). The function of the illusions of control and freedom. American Psychologist, 28, 417-425.

Marx, M. B., Garrity, T. F., \& Bowers, F. R. (1975). The influence of recent life experiences on the health of college freshmen. Journal of Psychosomatic Research, 19, 87-98.

O'Leary, A. (1985). Self-efficacy and health. Behaviour Research and Therapy, 23, 437-451.

Peterson, C., Bettes, B. A., \& Seligman, M. E. P. (1985). Depressive symptoms and unprompted causal attributions: Content analysis. Behavioural Research and Therapy, 23, 379-382.

Peterson, C., Luborsky, L., \& Seligman, M. E. P. (1983). Attributions and depressive mood shifts: A case study using the symptom-context method. Journal of Abnormal Psychology, 92, 96-103.

Peterson, C., Schwartz, S. M., \& Seligman, M. E. P. (1981). Self-blame and depressive symptoms. Journal of Personality and Social Psychology, 41, 253-259.

Peterson, C., \& Seligman, M. E. P. (1984). Causal explanations as a risk factor for depression: Theory and evidence. Psychological Review, 91, 347-374.

Peterson, C., \& Seligman, M. E. P. (1987). Explanatory style and illness. Journal of Personality, 55, 237-265.

Peterson, C., Semmel, A., von Baeyer, C., Abramson, L. Y., Metalsky, G. 1., \& Seligman, M. E. P. (1982). The Attributional Style Questionnaire. Cognitive Therapy and Research, $6,287-299$.

Peterson, C., \& Villanova, P. (1986). Dimensions of explanatory style. Unpublished manuscript, University of Michigan.

Peterson, C., Villanova, P., \& Raps, C. S. (1985). Depression and attributions: Factors responsible for inconsistent results in the published literature. Journal of Abnormal Psychology, $94,165-168$.

Rabkin, J. G., \& Struening, E. H. (1976). Life events, stress, and illness. Science, 194, 1013-1020.

Richter, C. P. (1957). On the phenomenon of sudden death in animals and man. Psychosomatic Medicine, 19, 191-198.

Rodin, J., Timko, C., \& Anderson, S. (1985). The construct of control: Biological and psychosocial correlates. In P. Lawton \& G. Maddox (Eds.), Annual review of gerontology and geriatrics (Vol. 5). New York: Springer.

Schleifer, S. J., Keller, S. E., Siris, S. G., Davis, K. L., \& Stein, M. (1985). Depression and immunity. Archives of General Psychiatry, 42, 129-133. 
Seeman, M., \& Seeman, T. E. (1983). Health behavior and personal autonomy: A longitudinal study of the sense of control in illness. Journal of Health and Social Behavior, 24, 144-160.

Seligman, M. E. P. (1975). Helplessness: On depression, development, and death. San Francisco: Freeman.

Suls, J., \& Mullen, B. (1981). Life events, perceived control, and illness: The role of uncertainty. Journal of Human Stress, 7, 30-34.

Taylor, R. B., Denham, J. R., \& Ureda, J. W. (1982). Health promotion: Principles and clinical applications. Norwalk, Connecticut: Appleton-Century-Crofts.

Wallston, K. A., \& Wallston, B. S. (1982). Who is responsible for your health? The construct of health locus of control. In G. S. Sanders \& J. Suls (Eds.), Social psychology of health and illness (pp. 65-95). Hillsdale, New Jersey: Erlbaum. 